\title{
Serious Games and Education: Lessons from South Korea
}

\author{
Juhyung Shin \\ Ph.D. Student \\ Graduate School of Core Ethics and Frontier Sciences \\ Ritsumeikan University \\ Kyoto, Japan
}

\begin{abstract}
Taking the example of Korea, this paper argues that Serious game should not be considered as purely educational and fundamentally functional, without taking into account that they also need to be fun. This neglect of the importance of fun, which has led to the failure of the educational use of serious games in Korea, is due to the fact that fun is generally seen as the opposite of what is educational and functional and to the Korean government's efforts to respond to social criticism of games as addictive and harmful. Analyzing one successful Ki-neung-seung (Serious game in Korean) I inquire into the characteristics that made it successful compared to other games. In conclusion, I argue that, beyond this particular example, the conception of games is fundamental to policy making and for social attitudes towards digital games and how we should conceive of serious games for wider applications in broader contexts.
\end{abstract}

Keywords: Education, Serious games, Ki-neung-seung games, South Korea, Fun

\section{Introduction}

Digital games have become an important part of our life, and with the remarkable development of new technology there are more various kinds of games than ever. Games are now central for our daily life, not only for leisure but also as something that can be beneficial, especially for education and social learning. In A Theory of Fun for Game Design (2005), Koster argues that all games intrinsically have a component of learning since the player learns the rules of the game simply by playing it. He also argues about the place of fun in games and its relationship to the learning process. Other researches point to the conclusion that digital games learning might have a positive effect on players' learning ability in general (Castro, 2012; Gee, 2004, 2005; Kafai, 1995; Prensky, 2001; Squire, 2005, 2008; Wi et al., 2006, Yoon, 2011). Even though the evidence on which these results rest is limited and they remain insufficient to convince everyone of the advantages of digital games for education, it seems clear that some of the characteristics of digital games (interactivity, feedback and problem solving), help students to mastery through repetition; and also, lead them to become more immersed in a given topic and to actively participate in the learning process.

Games are a good tool for stimulating motivation and participation. However, the idea of using digital games for other purposes than entertainment remains a challenging one because dominant social norms and culture in general are suspicious of them. This negative attitude is at the base of most objections when the issue of using digital games as learning tools is raised. Nonetheless, the fact that digital games inherently provide a learning experience needs to be taken into account. It should constitute the starting point of any study on the relationship between digital games and education. Here are but a few examples, studies and experiments which indicate that digital games can be successfully used for various purposes other than simple leisure: using GPS and integrating the real world in games, for example Pokemon Go or Ingress which gained widespread popularity and became a social phenomenon; Minecraft ${ }^{1}$ is used for education: Hillary $2016^{2}$ was used during the American presidential election campaign and MADRID ${ }^{3}$ aims at social changes in relation to terrorism.

\footnotetext{
${ }^{1}$ The most widely used "sandbox game" in education. Designed by Markus Persson, and published by Mojang.

${ }^{2}$ Developed by Clinton campaign in 2016.

${ }^{3}$ Released by Newsgaming in 2004. 
In opposition to COTS (commercial off-the-shelf games), some of the games listed above are referred to as "Serious games" (hereafter SG). The concept of SG was originally proposed by Abt (the first use of the term is in 1970) and his definition is still the most cited. Even though, when it was introduced, many types of games did not yet exist and the game industry was not established as it is today. Abt defined SGs as games that have "educational purposes" (particular, "specific purposes" purposes) in opposition to games that are only played for having fun. These purposes may be education proper, social welfare, military, political, etc. Another definition of SGs was later proposed by Sawyer (2002) and through the Serious Games Initiative the concept of SG became widespread and shared by many researchers and/or game designers. Michael and Chen (2006) define SG as a game for which entertainment, enjoyment, or fun are not the primary purpose.

Wolf, Mark et al. (2012) in their encyclopedia of video games, define SG as "A game that has been designed for a reason rather than to just entertain." Kim (2017) defined them as "games that are developed with the aim using them for various social issues" and discussed their advantages in his book. Finally, according to the Korea Game Dictionary (Lee \& Han, 2016), SGs are "Games that are developed for specific purposes, other than mere entertainment, that offer motivation, direct feedback, and help us in life. Furthermore, they bring benefits or positive effects in various fields."As we can see, there are many differing definitions, but they all agree that SGs are games whose goal differs from what is usually expected from digital games, i.e. entertainment. Although the various understandings of SG make it difficult to find a universally agreed upon definition; they all retain what constitutes the core of Abt's definition.

In recent years, the popularization of smartphone and handheld console games have increased the use of digital games, and made them easier to access learning tools. While many European countries actively use digital games for education and learning, this is not the case in Korea, where the use of digital games in education, especially inside the classroom, remains limited. One of the goals of this paper is to inquire into the reasons for this situation. Many reasons have previously been invoked to explain the limited use of digital game in education in Korea. For example, research related to digital game-based learning has focused on teachers' and parents' perspective and understanding of digital games (especially their worries concerning the use of games and game addiction) with an emphasis on their lack of skills and knowledge of games, both as a new technology and as a learning tool.

This paper proposes a different approach. The fact that SGs are often considered as purely educational and thus fundamentally functional, without taking into account that they also need to be fun is, I argue, the main cause of the limited success of SGs as educational tools in Korea. This neglect of the importance of fun is primarily due to the fact that fun (a main characteristic of games) is generally seen as the opposite of what is educational and of what is functional.

Significantly, the translation of SG in Korean is "Ki-neung-sung ge-im; meaning Functional Game (hereafter KG)." This terminological choice is far from irrelevant to the issue of the educational use of SG and revealing of the difficulties encountered in trying to use them for education in Korea. It is important for SGs to have a clear learning objective, but fun is what motivates us to participate voluntary in the learning process. I argue that this, the role of fun, is the main point in using digital games as a learning tool and that in Korea KG have often failed because they overlooked the importance of fun. This is true, not only for learning in school or the academia, but also when SGs are used for other social purposes.

In the remainder of this paper, I will first rapidly summarize the early history of the educational use of digital games and SGs in Korea. Then, I indicate some of the factors that have led to conceiving serious games essentially as KGs, that is as functional games, before analyzing one successful Korean SG and inquiring into the characteristics that made it successful compared to other SGs (or KGs). Finally, I discuss the importance of the conception of games in relation to policy making and to social attitudes towards them, before proposing how we should conceive of SGs for wider applications in broader contexts.

\section{Early history of digital games and education in Korea}

Even though Korea is one of the leading countries in the game industry, the first trials at using digital games as educational tools only began in the mid to late 2000s. A trial at using games for education was held in Chung-Ang

\footnotetext{
${ }^{4}$ Serious Game Initiative was established in America 2002 and it is related to serious games research and use.
} 
University in 2006. The results indicated an improvement in the players' self-efficiency, their ability to become active learners, and an increased level of interest in the class (Wi, 2009, 2014; Wi \& Won, 2009).

In 2008, using digital games for teaching English was tried in a high school English class. ${ }^{6}$ In 2009, the Korean government ${ }^{7}$ adopted G-learning in the form of a project named "G-learning project for Yeon-gu-hak-kyo," in some elementary schools in an effort to expand the use of digital games for learning and a variety of genres of PC games for education were released. Digital games were also used for learning history. Generally, the games used in education projects included online RPG games like Goonzu ${ }^{8}$ and Ger-Sang. ${ }^{9}$ Even though none of the games used for education in these early trials were developed for educational purposes, they showed very encouraging results for the educational use of digital games (Wi et.al., 2009). These initial trials, however were not continued. Therefore, before 2009, even if there was some research related to the use of digital games in education (Wi, 2006), only a few studies examined issues concerning the use of digital games as educational tools in Korea. Following the G-learning movement, ${ }^{10}$ this research started to appear actively. After 2010, using digital games for education, i.e. G-learning and SG games, became more frequent in various fields, education, social welfare, or job training. Nonetheless, SGs remained limited to particulars actors of education and only a limited number of genres of games were used. Even though research had proven that digital games could be effective educational tools, due to the low profit of game companies' many games were discontinued or the service was stopped. It is difficult to conclude anything definite concerning SGs from these early experiments because, as mentioned earlier, in most cases commercial games were used. It is only later as the advantages of using games suitable for education became evident that games were specifically developed for educational purposes. ${ }^{11}$

Table 1: The list of cases on KGs and/or Game-based learning in Korea

\begin{tabular}{|c|c|c|}
\hline & Year & Details \\
\hline 1 & 2005 & $\begin{array}{l}\text { E-sports contest, especially for the disabled students (aims to encourage the use } \\
\text { of digital games as an effective tool for education and to inform that digital } \\
\text { games can also be useful in terms of communication, motivation, and } \\
\text { achievements). }\end{array}$ \\
\hline 2 & 2006 & Seo-Jeong elementary school: Using Goonzu for Politics. \\
\hline 3 & $2007 / 2008$ & $\begin{array}{l}\text { Cheung-Myung high school: Using Goonzu for Economy, Politics/ English. } \\
\text { Game and leisure activities space HAPPY SPACE. }\end{array}$ \\
\hline 4 & 2009 & $\begin{array}{l}\text { G-learning project for Yeon-gu-hak-kyo: Yeon-gu-hak-kyo simply means } \\
\text { "schools for this research." Using games for Science, Math, and English. }\end{array}$ \\
\hline 5 & 2014 & STEAM G- learning: Using tablets with games for English. \\
\hline 6 & $2016 / 2017$ & $\begin{array}{l}\text { Support serious games dealing with awareness of environments issues, or social } \\
\text { problems to promote serious games in general. }\end{array}$ \\
\hline
\end{tabular}

\section{From Serious Games (SG) to Ki-neungseung Games (KG): The Government's influence and KGs Failure}

A more general use of SGs as a new learning tools requires empirical evidence, it demands that we examine facts concerning how effective SGs' are. There is also a need for clarity to reduce, if possible, the social suspicion toward digital games. In Korea, one of the main causes that makes these two goals -clarity and empirical evidences- difficult to reach is confusion about what SGs are (or should be).

\footnotetext{
${ }^{5}$ This first trial at using digital games for educational purposes in Korea was designed for university students in economy and management classes.

${ }^{6}$ At the Cheung-Myung high school, where the "Goonzu G-Learning" project was implemented.

${ }^{7}$ Both the Ministry of Culture, Sports and Tourism and the Ministry of Education were responsible for this project.

${ }^{8}$ The setting for Goonzu is the Choson Dynasty (1392-1910), the longest imperial dynasty of Korea. In fact, this game is not classified as a SG officially, but because of elements of seriousness are included, Goonzu has been evaluated as an effective educational digital game by studies dealing with the use of digital games in education.

${ }^{9}$ The setting of Ger-sang is also the Choson Dynasty. It is a MMORPG game.

${ }^{10} \mathrm{G}$-learning stands for game-based learning or game learning and using digital games in the learning process.

${ }^{11}$ For more information of cases used for education see the Table1. 
As mentioned earlier, the definition of SG in Korea focuses on the serious aspect of such games. "Serious" is conceived as the opposite of "fun" or "entertainment."In some cases, this goes as far as to imply that the game should solely be used for transmitting a set of instructions. There are then particularities related to the use of digital games in education in Korea as a result of the fact that SGs are included among "Ki-neung-seung" games, functional games.

Originally it was the effort to reduce the negative perception of digital game and to promote their wider use that lead to the diffusion of the term KG. The term started to appear frequently between 2007-2008, and was used to distinguish these games from "edutainment," games with an educational content, or "educational games," terms that had been used until then.

The progressive transformation of KGs into purely functional games -and thus less and less like SGs- can be seen by comparing an early conception of the role of KGs to a later one according to KOCCA (Korea Creative Content Agency). ${ }^{12}$ At first, KGs were digital games used as a tool that bring about change through learning and training. Furthermore, in serious games fun and immersion -which are central characteristics of games- work effectively for education or as cognitive therapy (KOCCA, 2013). According to the refined definition of 2013, KGs are "games which have fun and effect" and "games both for personal and public profit that bring about effects." In this later definition, the "functional aspect has not changed (KOCCA, 2015)" but it has been emphasized. At the same time as SGs other terms like "nice games" appeared and some of the games reviewed earlier are called "chak-kan" games, which translates as "good games." 13 These terms, nice or good games, also served the function of giving a positive image of digital games. "Edu-games" are also closely related to SGs, and the two terms often refer to the same games. These various terms cannot be clearly distinguished and their meaning is only slightly different. However, all insist on the functional aspect of these games and they are similar in that they share a "positive" meaning. These terms are used to indicate that these digital games do not have any "harmful" influence. If we ask, "what are SGs in Korea?" According to these definitions, in Korea SGs are different because they are conceived as KGs, as fundamentally functional. Additionally, -as we will see later- SGs/KGs are also seen as an alternative solution for the recovery of the Korean games industry. Thus, Korea shows some particularities compared to other countries in the SGs field. Most revealing of these particular characteristics is the transformation of the term SGs into KGs as the usual translation of SGs. But the issues and misunderstanding related to KGs are not merely a linguistic problem. An important underlying issue is the strong influence of government's policies which was the main factor that lead to the transformation of "serious games" into "functional games."

In most countries, for instance Japan, serious game studies are done either by academics in universities or directly by game companies like Nintendo, Namco and so on. In USA, not only the governments, but also many nonprofit institutions lead the development of SGs and implemented related projects. These institutions are well known for their activities relating to SGs. Although the influence of the American government was originally central, because what is considered to be the first SG was elaborated for the US Army, that influence became less important in later developments. However in Korea, the government took an important role and became the main actor in the use and development of SGs (or KGs). While projects were generally run by non-profit organizations or hospitals, the most actively engaged actor related to SG in Korea was the government through institutions like the Functional Game Promotion Agency. From the beginning, the Korean government also took measures of regulation towards digital games that revealed an ambivalent attitude that is uniquely found in Korea. The term $\mathrm{KG}$ and its fast diffusion reflect two contradictory attitudes of the Korean government.

Accompanied by a better internet service environment, due to the fast growth of internet penetration, the spread of home computers made Korea the highest IT country in the World, where digitalized education was considered a prerequisite and commonly found in schools. Korean game industry developed rapidly and Korea became one of

\footnotetext{
${ }^{12}$ KOCCA was created in 2009. This government department absorbed previous existing separated departments, including the Korea Game Industry Agency which was dealing with games. The official function of KOCCA is to support various Korean contents (Manga, Drama, K-Pop, games and etc.).

${ }^{13}$ Chak-kan means "good" in Korean. In this context, the term indicates that these games are good game for educational purposes.
} 
the leading countries in the game industry. PC bangs ${ }^{14}$ and the population playing digital games sharply increased. This led to the creation of a sub-culture related to digital games, the game industry directly giving rise to a new social phenomenon. Furthermore, during the period called the "Golden age" numerous digital games were released, most were computer-based games and online MMORPG games that became incredibly popular.

The government realized that game industry contributed to the Korean economy, so it passed various laws to support and encourage it. It also held events and initiated projects related to digital games to encourage the gamerelated industry, like e-sports and others. However, as mentioned earlier, despite that SGs first appeared in Korea around 2004, early trials at defining SGs and research related to adopting digital games beyond "fun and entertainments" only took place about 8 years later. The cause of this long delay is likely to have been the many arguments against the use of digital games for purposes other than entertainment (especially education) that were prevalent in Korea. They are related to what has been viewed as "digital games side effects" according to the Media and some of experts from government's departments of education or health. ${ }^{16}$

Dangers that are illustrated by the Media's extensive report on game addiction and game-related crime, warning the public of how dangerous digital games are. In view of this, it is clear that a positive attitude towards games is not dominant in Korean society. To the opposite, the negative perception of digital games is quite strong and has led not only to regulating the game industry, but also in 2011 to regulations concerning digital games themselves. ${ }^{17}$ For example, the Online Game Shutdown Policy also called the "Cinderella Law" ${ }^{18}$ which aims to reduce the amount of time available for playing games for children under the age of 16 . Moreover, there are strong requests by some legislators (KOCCA, 2012) for even stricter regulations dealing with digital games, which are considered to be possibly as addictive as gambling, alcohol, or drugs. These demands are supported by the education and religious sectors.

In an attempt both to satisfy critics and to protect the game industry, which brings much to the country's economy, also to correct the purely negative image of digital games and to moderate demands for stricter regulations, the government hoped to achieve a breakthrough thanks to the idea of KGs.

The Korean government supported the design and development of KGs throughout the domestic gaming industry. In 2005, it collaborated and shared information with SGI (Serous Games Institute) in the UK. Furthermore, the Korean government extended projects related to KGs. In 2010, KAIST's (Korea Advanced Institute of Science and Technology) Functional Game Lab was founded. Its aim is research and development related to SGs and the widespread diffusion of KGs in society. Its slogan is: "to exploit the beneficial functions of games in various fields such as education, military, medication, social campaigns." The government's action in favor of KGs can also be seen in another report from the Korean Game Industry Promotion Agency (2007), and in an evaluation of educational games done by the government in which some games were presented as successful cases of KGs by the Contents Research Institution.

It should be remembered that the computer-based culture of Korea greatly influenced the government's policy towards SGs (KGs). In Korea, the computer is closely associated with "Education" and "Learning." Therefore, even parents and teachers who have a negative attitude of digital games do not object to letting children use computers. This positive image of the computer was used to promote the educational use of digital games (Yoon, 2015). However, the government recently has had to replace the term "functional game," because so far most of the Korean government's KGs did not work properly, or rather completely failed both on the marketplace and in educational fields. In many cases these projects were simply discontinued.

\footnotetext{
${ }^{14} \mathrm{PC}$ bangs are places for playing online based game, especially playing computer games with fast internet connection. They are equipped with the latest model of computers. The word "bang" means "room" in Korean.

${ }^{15}$ From mid 1990s to early 2000s is called the "Golden age of Korean games (Yoon et. al, 2014)."

${ }^{16} \mathrm{KOCCA}$ not only support games but also reported the social negative attitude towards games.

${ }^{17}$ For example, "Hope for education: Overcoming game addiction. (2009)", "Game addiction: Games can kill you. (2009)."

${ }^{18}$ The Game Shutdown Policy is called the Cinderella Law because the access to game systems are shutdown from am 12 to am 6 o'clock. This regulation is a youth protection act for juveniles. However, it is often criticized as an infringement of the right to play games. 
That is why, since 2015, KGs are no longer seen in the game-related events that were original named "Ki-neungsung game shows." Instead, the term "Good Game show" is now used.

Some research was made to show the beneficial aspects of KGs (SGs). However, it was unable to provide a concrete model or norm of assessment. Actually, successful cases of using KGs, especially among those that were initiated by the Korean government, have been hard to find. From 2009, 51 game projects were developed or supported by the Korean government, of these $40 \%$ are discontinued, among the remaining $60 \%$, many games were never released even though the announced date of released is now long passed (KOCCA, 2010). Why? Many games, for example, Star Stone, were judged by players as not being fun:

This common judgment does not prove, but it does suggest that, rather than exclusively focusing on visual and sound effects, including a fun factor, as found in commercial games, are important. If one looks at the comments from the community, the main reason why these games were a failure is simply because they were boring and not enjoyed by players. ${ }^{19}$

\section{A Successful Case of SG in Korea: analysis of Hanja-maru}

One successful SG is Hanja-maru a game that was developed by eduflo ${ }^{20}$ and published by NHN a most famous game company at that time. Hanja maru is a Kanji (Chinese characters) learning game designed to provide enjoyable and engaging learning experiences to children. This game also has a straightforward control system.

NHN was famous for gambling type of games, somewhat like poker. It decided to change its image and established The Institute of Functional Games that actively promotes the benefits of KGs. NHN conducted experiments to show Hanja-maru's effectiveness in Kanji learning cooperating with Seoul National University's Institute of Psychology which indicated that using Hanja-maru as a learning tool was a highly effective way to learn and memorize Kanji and also had positive effect on long-term memory (Lee, 2011). The service for this game closed in 2012, nonetheless it still has fan communities that are looking forward to playing again (there are four official communities).

When Hanja-maru was released, the media reported positively. The reason of the success of this game seems related to the fact that it was developed and conceived entirely by a game company which had the know-how to make the game fun in combination with educational factors, and that was also eager to get support from parents. The founder of eduflo indicated that when game companies make SG, they try to make entertainment games that have serious content, while the government tries to develop educational content into something that "looks like" a game and then calls it SG (KG). Not surprisingly most of these government attempts ultimately fail. He also underlined the importance of taking into account both the parents' and implicitly also the teachers' point of view as well as of convincing them to use games as an educational tool.

While eduflo developed the game, NHN was its publisher and its point of view about fun and education is slightly different from that of eduflo. It defines SG as "games in which players feel the effects and benefits while playing and having fun, which is important for learning." In other words, this company tried to produce a game that had educational effectiveness and tried to include fun. NHN recognized that fun is necessary in games. Hanja-maru's game play is similar to that of games that are popular with elementary school students as it is also a game whose target audience is elementary school students. We can see that these two companies' points of view were different from the Government's in that they recognized the importance of "fun." This example suggests that in using digital games as an effective educational tool, it is important to provide sufficient "fun" as well as learning content.

If the game emphasizes too much fun or too much learning, for example a particular knowledge or skill, it will either provide only enjoyment without any learning experience or a boring experience that will stress the players. In either case, such games cannot bring about leaning and cannot support an effective learning process. Hanjamaru is targeted for learning the basic structure of kanji word.

\footnotetext{
${ }^{19}$ This is the frequent comments found in famous online game communities such as RULLWEB (Retrieved August 30,2018 from http://bbs.ruliweb.com/game/79147/board/read/3321452).

${ }^{20}$ This company focuses on making educational contents for ICT education. The name of this company eduflo combines education and flow to indicate that using games as a tool can immerse children in education. Eduflo was an independent company but also supported by the Korean government.
} 
The rules of the game are similar to those of action games and the skills needed for playing the game vary with the game's levels and depend on the player's experience. Hanja-maru also has a story; rescue the world from monsters that threaten it and become a hero. Each monster has a Kanji on its chest, and when players attack monsters, they should identify the meaning and pronunciation of the kanji. Moreover, if players defeat many monsters, they can gain different kinds of Kanji and create their own Kanji board which increases their experience, skill points and treasure chests (which include random items).

In this game, there is a variety of feedback (rewards) offered to enhance the fun, that leads players to immerse themselves in the game. Feedback is offered immediately after the player successfully finishes a mission or quest. Players receive food to replenish their energy, clothes or weapons to customize their characters, and these items can be exchanged. Hanja-maru has been evaluated as successfully balancing between education and the "fun" factor both by KOCCA and by the media. This evaluation is quite different from that of other KGs that were ignored by students and teachers.

Hanja-maru further offers auditory effects related to Kanji words, which enhances both visual and auditory learning. It also has high reflexivity, interaction and self-checking missions where players can figure out what they learned. If Hanja-maru can be considered a more suitable type of serious game which includes both "fun" and an educational purpose, it is because it focuses on the "game" more than on its "functionality." This focus makes players become active learners without drawing unwelcome attention to what they should memorize or feel obliged to study about Kanji (Lee, op. cit. p. 22) and it has proven its educational efficiency. An experimental study by KOCCA and Seoul National University (2011) showed that playing Hanja-maru 15 minutes is conducive to learning 2 or 3 new Kanjis even though players are not pressured to memorize them.

Even though there is an official website that offers a community for players to join, players have spontaneously created their own community where activities and interaction have grown along with the popularity of Hanjamaru. Social use is related to interchange among multi-players and this game offers a place to interchange with other players more than any another KG.

Overall, this game satisfies all the criteria of what a KG (SG) should meet and is also "fun." To the opposite, most SGs (KGs) for education tend to overemphasize the functionality of the games; the stories are generally too simple and uninteresting. In particular, the repeating practice process is considered as the most important part of a game in relation to education and the story line is disregarded as a secondary factor. The most common types of SG developed by the governments only include limited or no game fun factors inside the game. To exclusively focus on the serious or functional aspect of an educational digital game cannot bring out the full educational potential of this digital tool.

In education, the fun factors of the SGs are used to serve seriousness. Between seriousness and fun, games for education should be designed to satisfy both purpose and fun. Through reviewing existing KGs, we can see that even though the fun factors of games are relevant, in serious games for education they are not considered within the basic factors of digital games. That is why in Korea so many SGs fail to keep the attention of players or to gain support from parents and teachers. It also helps to explain why parents and teachers develop a negative perspective toward digital games. Designing games that fulfill the two requirements of being educational and also fun will allow us to bring out their full potential as educational tools.

There are numerous different kinds of fun inside games and fun depends on players. As several research showed, the game culture of South Korea is based on online games. South Korean game culture is online games oriented. These kinds of games have great popularity as can be seen from the game industry. The particularity of the Korean game culture and market is that it is mostly based on massive online players games (Jeon, 2005).Therefore, one important factor for engaging players and for players to become player learners (to successfully learn through playing games), is offering social interaction and social rewards. In this case, Hanjamaru provided a chat system, an active bulletin board, and community activities. Social interaction was one of its central characteristics compared to current solitary playing of serious games. In this type of the games, what makes the game fun is closely related to fun in social interaction, what Lazaro (2004) calls "People fun.",21

\footnotetext{
${ }^{21}$ Lazaro proposed there are four kinds of fun: Hard fun, Easy fun, Serious fun and People fun. Especially, People fun is a fun of amusement from competition and cooperation just like a friendship. 
Hanja-maru was an online role-playing game. Players could chat inside the game while playing. Furthermore, there was a bulletin board for players to communicate outside the game. It is true that compared to commercial MMORPGs, this aspect of the game remained limited, nonetheless we can see from the Hanja-maru case, not only that many different factors contributed to the players' fun, but also that one factor in particular differs from what is found in most KGs, people fun.

Fig1: A screenshot of Hanja-maru, cute graphics style used for the game. Straight forward interaction, players can chat with other players (Source:GG 게임.RetrievedAugust30,2018from http://www.ggemguide.com/game_view.htm?uid=747).

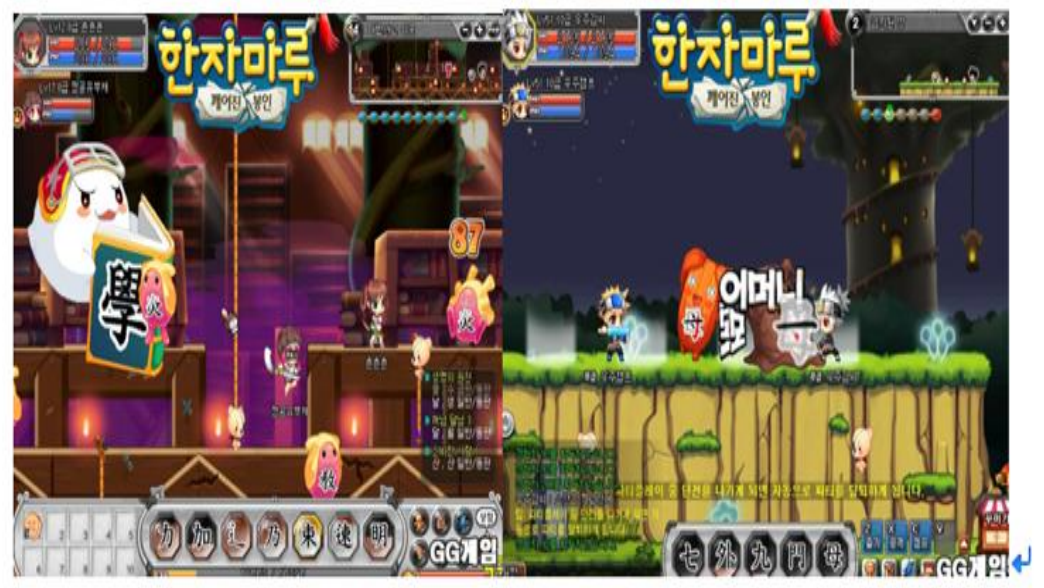

\section{Conclusion}

In this paper, I explored some of the factors that affected to the definition of SG in Korea; how SG changed into $\mathrm{KG}$; and some of the consequences of conceiving serious games as essentially functional games. When connecting digital games to various fields, especially learning and education, we need to rethink what functionality is and how SGs are defined. In Korea, the emphasis is placed on functionality as opposed to entertainment, and digital games are criticized for being sensational and violent. The term "functional" came to be used to indicate a "good game" as opposed to normal games which are viewed as a "bad game." SGs are defined as games which have other purposes than mere entertainment, but to succeed SGs also needs "normal" game factors such as entertainment or enjoyment.

Given the role of an object as a tool, it should be designed to be easily and diversely used by anyone rather than require overly complicated or specialized technical skills that take several years to master. Because digital natives' life styles (Prensky, 2001) is based on digitalized environments, they have a particular capacity to acquire knowledge and skills through digital media. KGs that only emphasize functionality are simply ignored by players (also learners). Players (learners), students, do not find those games motivating nor do they encourage them to continue and to try again. Excessive focus on "functionality" reveals a misunderstanding of the nature of SGs that prevents us from developing the full potential and possibilities of digital games as educational tools. Serious games must be educational, but functional games that are only interested in the purpose they are trying to promote are uninteresting and ineffective tools. Lee (2014) suggests that KGs can help reduce the negative social perspective on digital games, but that will not happen if KGs are conceived as purely "functional" or "effective" games that are the opposite of normal games that we continue to view as harmful.

KGs as they now exist constitute a contradictory attempt to think about how to connect games and education, how to use games otherwise than as mere entertainment. It is crucial for us to discover the correct connection. To do so, it is important to "Return to the origin", that is to the essence of games. Rather than being bound by the term functionality, we need to focus on how we can combine and balance "fun" and "educational content." Recently, the term "Play-Learner" has been introduced to show the potential of SGs to engage learners. 
Loh et al. (2015) define a play-learner ${ }^{22}$ as someone who plays as he learns and learns as he plays, ie. someone who trains and learns through serious games. The particularity of this concept is that it suggests that for SGs to be effective players should be play-learners while most current serious games force players to be merely learners. Games offer players opportunities to have different types of experiences, various levels of experience, as well as an opportunity to acquire, to learn something. This is true of all games, not only of serious games. The important point is to select a game that fits the desired purpose and to use it as a tool.

When reflecting on the use of SGs in different fields and not just for entertainment, we should take account the concept of play learners and the importance of fun that motivates players in the learning process. Beyond becoming a learner, users should enjoy the game play and participate actively; that is the core meaning of play learner and the way to maximize the educational advantages of games. McGonigal (2011) reminds us that one of the essential traits of games is that players are "voluntary participant" and being a voluntary participant is the authentic meaning of becoming a play-learner in any formal or informal learning setting.

In Korea, the misleading term KG, government's regulations, and the development of inappropriate games that led us to view serious games as not fun, have hindered our ability to use digital games for a variety of social purposes. We are living today with technologies that have changed our life radically from the past, it is therefore important to discuss how to use them and how to make them beneficial. Even though this paper focused on the South Korean case, the issue it addresses goes beyond and is more universal. How serious games can and should be used for education is something that concerns all of us.

\section{References}

Abt, C. (1987). Serious Games. Lanham. University Press of America.

Castro, J. (2012). Learning and teaching art though social media. Studies in Art Education, 53(2), 152-169.

Gee, J. P. (2003). What Video Games have to teach us about Learning and Literacy. London: Palgrave Macmillan.

Gee, J. P. (2004). Situated Language and Learning: A Critique of Traditional Schooling. London: Routledge.

Gee, J. P. (2005). Why Video Games Are Good For Your Soul: Pleasure and Learning. Melbourne: Common Ground.

Jeon, K. R. (2005). The Astetics of Digital games. Seoul: sallim. (전경란.(2005). 디지털게임의미학. 서울: 살림.)

Kafai, Y. B. (1995). Minds in play: Computer game design as a context for children's learning. Mahwah, NJ: Lawrence Erlbaum.

Kim, S. G. (2017). Kyoyuk, gaimchoromjugyora. Seoul: Hongrung Publishing Company. (김상균. (2017). 교육, 게임처럼즐겨라. 서울:홍릉과학출판사.)

Kim. J. B. (2009). Hope for education: Overcoming game addiction. KUKMINILBO. August 10, 2009. Retrieved August 30, 2018 from http://m.kmib.co.kr/view.asp?arcid=0921382182

Korea Creative Content Agency. (2010). Guide to Korean Games Industry and Culture: White Paper on Korean Games. Seoul: Korea Creative Content Agency.

Korea Creative Content Agency. (2011). Guide to Korean Games Industry and Culture: White Paper on Korean Games. Seoul: Korea Creative Content Agency.

Korea Creative Content Agency. (2012). Guide to Korean Games Industry and Culture: White Paper on Korean Games. Seoul: Korea Creative Content Agency.

Korea Creative Content Agency. (2013). Report on Current Practice of Serious games. Seoul: Korea Creative Content Agency.

Korea Creative Content Agency. (2015). Guide to Korean Games Industry and Culture: White Paper on Korean Games. Seoul: Korea Creative Content Agency.

Korea Creative Content Agency. (2017). Guide to Korean Games Industry and Culture: White Paper on Korean Games. Seoul: Korea Creative Content Agency.

Korean Game Industry Promotion Agency. (2007). Korean Game White Paper. Seoul: Korean Game Industry Promotion Agency.

Koster, R. (2005). A Theory of Fun for Game Design. Paraglyph Press.

Kwang, J. U., et al. (2008). Games and Culture Study. Seoul: communication books. (강지웅외.(2008). 게임과문화연구.서울: 커뮤니케이션북스.)

\footnotetext{
${ }^{22}$ The concept of Play-Learner was reference to Johan Huizinga's famous saying: "Let my playing be my learning, and my learning be my playing (Ibid., p. 12).” 
Lee, D. E. (2011). A Study on Combination Aspects of Fun and Learning in Educational Serious Games. Journal of the Korean society for computer game, 11, 15-24. (In Korean.)

Lee, D., Y. (2014). Game Effect. Seoul: Imagine. (이동연. (2014). 게임이펙트. 서울: 이매진.)

Lee, I. H., \& Han, H. W. (2016). The Game Dictionary. Seoul: Hainaim. (이인화, 한혜원. (2016). 게임사전. 서울: 해냄.)

Loh, C. S., Sheng, Y., \& Ifenthaler, D. (2015). Serious Games Analytics. Loh, C. S., Sheng, Y., andIfenthaler, D (Eds.), Cham: Springer International Publishing.doi: 10.1007/978-3-319-05834-45.

McGonigal, J. (2011). Reality Is Broken: Why Games Make Us Better and How They Can Change the World. New York: Penguin Group.

Michael, D., \& Chen, S. (2006). Serious Games: Games That Educate, Train and Inform. Boston: Thomson.

Min, T. W. (2009). Game Addiction. KUKMINILBO. December, 09, 2009. Retrieved August 30, 2018 from http://m.kmib.co.kr/view.asp?arcid=0002243785

Prensky, M. (2001). Digital Natives, Digital Immigrants Part 1. On the Horizon, 9(5), 1-6.

Sawyer, B. (2002). Serious games; improving public policy through games-based learning and simulation. Woodrow Wilson International Center for Scholars.

Sawyer, B., \& Smith, P. (2008). Serious Game Taxonomy. San Francisco, USA: Paper presented at the Serious Game Summit 2008. Retrieved August 30, 2018 from https://ssrn.com/abstract=294828

Squire, K. (2005). Educating the fighter. On the Horizon, 13(2), 75-88.

Squire, K. D. (2008). Video game-based learning: An emerging paradigm for instruction. Performance ImprovementQuarterly,21(2), 7-36. https://doi.org/10.1002/piq.20020

Wi, J. H., et al. (2006). Online-Games shake hand with Education. Seoul: Hankyungsa. (위정현외. (2006). 온라인게임, 교육과손잡다. 서울: 한경사.)

Wi, J. H. (2006). Utilizing Online Game as a effective learning materialConsideration of a Business Strategy Lecture by Utilizing Online Game, "Goonzu". Journal of the Korean society for computer game, 6(4), 25-37. (In Korean.)

WI, J. H. (2009). The Effects of Strategic Management Education Program Utilizing MMORPG - The Effects on Self Efficacy of Managerial Decision Making. Journal of strategic management, 12(2),135-149. (In Korean.)

Wi, J. H. (2014). Analyze a developing process of 3D STEAM based G learning contents. Journal of Korea Game Society, 14(6), 69-78. (In Korean.)

Wi, J. H., Jeong, D. B., \& Won, E. S. (2009). The efficiency of English teaching and learning utilizing MMORPG in high school. Modern English Education, 10(3), 194-216. (In Korean.)

Wi, J. H., \& Won, E. S. (2009). The Effects and Process of the Politics Instruction Utilizing an Online Game, 'Goonzu'. Journal of the Korean society for computer game, 9(5), 83-93. (In Korean.)

Wi, J. H., \& Won, E. S. (2013). A Case Analysis of Entry in Global Education Market focused on Public Education: The Entry of G-Learning (Game Based Learning) into a Public School System in USA. Korea Association for International Commerce and Information, 15(2), 109-128. (In Korean.)

Won, U. S. (2012). Efficiency of G-Learning (Teaching and Learning Methodology utilizing Game) adopted in an English Class for 5th Grade Elementary School Students. The Journal of the Korea Contents Association, 12(10), 541-552. (In Korean.)

Wolf, Mark J. P. (2012). Encyclopedia of Video Games: The Culture, Technology, and Art of Gaming. Mark J. P. Wolf and Santa Barbara (Eds.), CA: Greenwood.

Yonhapnews. (2009). Game addiction: Games can kill you. YONHAPNEWS. November 18, 2009. Retrieved August 30, 2018 from https://news.sbs.co.kr/news/newsMain.do

Yoon, H. S. (2011). A Study on Analysis of a Serious Game: A Online Game "Allep". Journal of the Korean society for computer game, 24(2), 33-41. (In Korean.)

Yoon, H. S., et al. (2014). Gaimipikeisheon, Sesangulpulreihada. Seoul: Hongrung Publishing Company. (윤형 섭외. (2014). 게이미피케이션, 세상을플레이하다. 서울: 홍릉과학출판사.)

Yoon, T. J. (2015). Digital ge-im munhwa yeongu. Seoul: Communication Book. (윤태진.(2015). 디지털게임문화연구.서울:커뮤니케이션이해총서.)

Other Resources (Games)

Hanja-maru, eduflo, 2009. (PC)

Hillary 2016, Clinton campaign, 20016. (iOS)

Ingress, Niantic, 2012. (Android, iOS)

Ger-sang, AK Interactive, 2002. (PC)

Goonzu, Ndoors, 2004. (PC)

MADRID, NewsGaming, 2004. (PC)

Minecraft, Mojang, 2009. (PC)

Pokemon Go, Niantic, 2016. (Android, iOS)

Star Stone, Vetoquinol korea, 2006. (PC) 